\title{
Analysis of the human resource management role in hospitals using Ulrich model
}

\author{
MohebbiFar Rafat ${ }^{1}$, Shams Mahboobeh ${ }^{1 \star}$ and Javadi Amir ${ }^{2}$ \\ ${ }^{1}$ Health Management Department, Qazvin University of Medical Sciences, Qazvin, IR Iran. \\ ${ }^{2}$ Department of Social Sciences, Qazvin University of Medical Sciences, Qazvin, IR Iran.
}

Accepted 19 June 2012

\begin{abstract}
Human resource (HR) management is regarded as a vital factor in organizations. Nowadays, the human factor is considered a unique strategic resource and key executive system designers of organizational processes. Based on progressive organizational thinking, the human resource is assumed as a major asset among company's production factors. The research goal for this paper is to evaluate human resource's role in specialized and sub specialized medical training hospitals of Iran, using Ulrich model. Research results indicated that the studies hospitals revealed an average quality in providing human resource services and none of the hospitals could close to $\mathbf{1 6 0}$ which is the high quality standard of human resources based on the Ulrich model. Besides, the results showed that there is a significant positive correlations between the service qualities and human resources; and "strategic partner role" considered as the strength and "staff support role" regarded as a resilient point in human resource management. Considering positive impact of strengthening the planning, management and training of health workers on the performance of this section, it would be possible to improve the capacity of human resource managers and the quality of healthcare services in the society.
\end{abstract}

Key words: Human resource management, excellence, role of human resources, health services.

\section{INTRODUCTION}

Human resource (HR) management is considered as a realm of this century's phenomena. Economic successes after World War II and the extensive development of certain Far East countries have introduced the human resource development in organizations and communities as quite an impressive factor (Mirsepasi, 2005). Human resources management is defined as identification, selection, hiring, training and development of human resources to meet the organizational goals (Saadat, 2007).

Human resource management is strategic in an integrated approach to management as the organization's most valuable assets, that is, individuals contribute in meeting the organizational goals (Ghelich, 2007). Scientific studies show that the results obtained from human resources are the most influential tools to achieve the

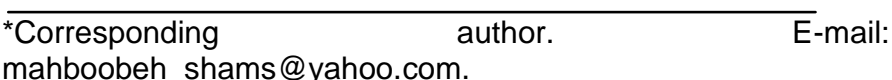

organizational excellence (Azar et al., 2004) and there is a correlation between the discernment to detect the human resource management and differences in human resource mana-gement performance in organizations (Schultz, 1997). Organizations that invest in appropriate fields of human resources, would obtain significant returns on the staff efficiency, customers, investors and organizations. HR professionals who want to create values for customers, employees and investors are required to think about their role (Ulrich, 1998).

Organizations providing health services should improve and strengthen their human resource management principles and rely on their own capabilities in order to have positive effects on their entire system (Schiffbauer et al., 2008). Therefore, the staffing and employing human resources should be planned as part of the organizational activities and healthcare issues; because other infrastructures such as healthcare organizations and health centers, sources of financial investment, services systems, information systems, payroll systems and so on affects directly the structure and function of 
human resources (Mostafayee, 2004).

Based on the study results by Friedman (2004), effective implementation of human resource management (that is, strategic partner, change agent, administrative expert and support staff) can indirectly increase the guild's credit which is an intangible organizational asset resulting in the effective implementation of these roles and increase in intangible assets of healthcare organizations like a brand reputation.

Healthcare providers and organizations, particularly hospitals, provide the public with the most important and fundamental health services (Torabipour, 2004) and is unique because of various experts and professionals working in a variety of services. Besides, there are at least three main reasons for attention to workforce issues in hospitals and health sector in general:

1. Hospitals depend on their human resources because of they are service based,

2. Human resources are allocated the high proportion of funds in the health sector,

3. Poor human resource management in this sector results in high economic and human costs (Mahdavi, 2006).

In line with this issue the importance of universities, especially comprehensive ones such as Tehran Medical Science University with its prominent role in the science, technology and innovation is known to everyone in Iran. Considering the necessity of change in the management attitude from traditional human resource management to an elevated type, attempts have been made in the present study to assess the role of human resource management at Hospitals in the University realm using the Ulrich (1997) model so that HR professionals could identify their strengths and improve their roles. In addition, comparing scores assigned in university hospitals, one may conclude the quality of human resources and examine the perception of quality so that the results can be utilized in future planning of human resources.

\section{LITERATURE REVIEW}

\section{Modern human resources management}

Permanent effort of organization for reaching the comprehensive assessment model and removing the shortcomings of traditional assessment methods resulted in emergence of business excellence models and national quality award in pioneer countries and then the other countries of world. Deming, Baldridge and the European quality models (EFQM) are among the most significant models which form the basis of other models. The models assess the organizational performance through TQM elements as the main criteria of assessment. They allocate pre-determined values to each field.
The said models are known as self-assessing models as well (Azar et al., 2004).

For moving toward the excellence, organization has to establish modern management systems. Factors such as organizational leadership, strategic planning, employees satisfaction and promotion, better use of resources, editing and applying the process are among the factors which can guide the organizations toward growth and development (Mirfakhraldini et al., 2009).

Organizations which make good investments in field of suitable human resources activities will gain noticeable output in field of employees' gains, clients, investors and organization. These human resources professional who are interested in value - creation for clients, employees, investors and organization, must revise their roles. The fact that human resources should be challenged is a super opportunity that can result in restructuring the said profession and its role in organizations. Generally, managing the said challenges, values and roles which highlight the future of human resources have emphasis on the capabilities of human resources (Ghelich, 2007).

\section{New roles of human resources management}

Fundamental changes in activities, trends and business of human resources management in the pass has made the human resources directors to abandon their traditional believes and accept new roles which differentiate their organizations.

As shown in Table 1, in recent year more time has been devoted to strategic planning and development of human resources trends. If value - creation is the future priority, new roles must be defined for human resources professionals. In recent years, the roles of these professional have been considered based on movement from operational to strategic, from qualitative, from policy - making to partnership, from short - term to long - term, from administrative to consultative, from duty - based to business - based, from introversion to extroversion and client - centering, from subjective to objective and solution - centering (Ghelich, 2007).

Based on said movements, the professionals' roles have been provided in a mixed rather than a separate way. The framework shown in Figure 1 describes the four key roles that must be played by the professional for creating value and realizing the partnership. Two items of the said framework shows the focus and activities of the professionals.

\section{Strategic human resource management}

This role focuses on aligning the human resources strategies and trends with business strategies. In order to fulfill the role, the professional tries to become a strategic partner for executing the business strategies. Through 
Table 1. Time spent on human resources activities (1991 to 1996) (Gehlich, 2007).

\begin{tabular}{lccc}
\hline Changing roles of human resource & $\mathbf{1 9 8 9}$ to 1991 (\%) & $\mathbf{1 9 9 6}(\%)$ & Difference \\
\hline $\begin{array}{l}\text { Keeping personnel record: collecting, understanding and keeping the } \\
\text { personnel data. }\end{array}$ & 22.2 & 15 & $\begin{array}{c}\text { Meaningful } \\
\text { decrease }\end{array}$ \\
$\begin{array}{l}\text { Control: } \\
\text { Ascertaining/ observing the organizational trends, regulations, legal } \\
\text { obligations and union's regulations. }\end{array}$ & 19.4 & 12 & $\begin{array}{c}\text { Meaningful } \\
\text { decrease }\end{array}$ \\
$\begin{array}{l}\text { Providing human resource services: Helping the execution and } \\
\text { management of human resource trends. }\end{array}$ & 35 & 31.3 & $\begin{array}{c}\text { Meaningful } \\
\text { decrease }\end{array}$ \\
$\begin{array}{l}\text { Developing the human resource trends: developing the new systems and } \\
\text { trends in human resource. }\end{array}$ & 14 & 19 & $\begin{array}{c}\text { Meaningful } \\
\text { increase }\end{array}$ \\
$\begin{array}{l}\text { Strategic partner: member of management team partnership in strategic } \\
\text { planning of human resource, organizational design and strategic change. }\end{array}$ & 11 & 23 & $\begin{array}{c}\text { Meaningful } \\
\text { increase }\end{array}$ \\
\hline
\end{tabular}

\section{Long-Term (Future) focus}

\begin{tabular}{|c|c|c|c|}
\hline & $\begin{array}{c}\text { Strategic Human } \\
\text { Resource Management }\end{array}$ & $\begin{array}{c}\text { Management of } \\
\text { Transformation \& Change }\end{array}$ & \\
\hline rocesses & & & Employees \\
\hline & $\begin{array}{l}\text { Management of the Firm } \\
\text { Infrastructure }\end{array}$ & $\begin{array}{l}\text { Management of Employee } \\
\text { Contribution }\end{array}$ & \\
\hline
\end{tabular}

\section{Short-Term Focus}

Figure 1. Roles of the human resource in formation of a competitive organization (Ulrich, 1997)

this, professionals increase the business capacity of strategies execution.

Converting the business strategies to human resource trends helps the business in 3 ways: First, the business becomes flexible against changes. Second, the business can better supply the clients' demands, since the client's service strategies change into special trends. Third, the business can realized the financial performance through more effective execution of strategies. The result will be strategy execution. Human resource trend will help the realization of business goals. The metaphor of this role is "HR as a strategic partner".

The professional become strategic partners when they participate in defining the business strategy, change it to operational plans and align the trends with business strategies. The main measure of as strategic director is to change business strategies into human resource priorities. The process that helps the identification of said priorities is called organizational diagnosis which includes organizational assessment in order to define the weak and strong points.

\section{Management of firm infrastructure}

Establishing the organizational infrastructure is the traditional role of the human resource. It requires effective design and execution of attraction and employment process, training, assessment encouragement, promotion and employees circulation throughout the organization. The professionals must ascertain the effective design and execution of said process. In spite of the decrease of said role and even its denial because of the attitude of professionals toward the strategic role, its 
successful execution depends on creating value for the business. The result is administrative efficiency. Professionals realized it in two ways: first, ascertaining the efficiency of human resource process, second, employing, training and encouraging those directors whom increase the productivity and decrease the losses.

The metaphor for the infrastructural role of the firm is "Administrative Expert". The professionals identify unnecessary costs, promote the efficiency and continuously identify better ways of doing works. For the purpose of efficiency, administrative experts must reengineer the work process permanently. In many companies, this is called "shared services" by which the administrative services of firm's divisions are divided while preserving the services quality for the operators (line directors, employees, senior directors). The term "shared services" points to the central provision of human resource services to the users. More clearly, the client / user define his/her required service level and then choose.

So, the user is the selector. These services may be provided via internal, telephone, consultation center, service centers in fields such as employees relationships, encouragement, training, welfare services.

\section{Management of employee contribution}

Here the role of professionals includes their partnership in issues, affairs and current demands of employees. In companies that consider the intellectual capital as the vital business source, the professional must work actively for developing the said capital. So, they support the employees through connecting the employee's contribution and the organization's success. The result will be management of employee contribution, increase of responsibility and capability among the employees.

Human resource trends must help the employees in showing their capabilities for doing good works and their commitment to the work. In a time that humiliating has weakened the psychological agreement between employer and employee, human resource directors can participate in business through supporting the employees and their needs. The metaphor for this role is "Employee Champion". This champion spends time for the employees and trains and encourages the directors of other divisions to do so.

Presence of supporters (Champions) who understand and supply the employee's need increase the employee contribution. Employee partnership in any business is necessary not only for themselves (social attraction of committed employee), but also because of its influence on the ability of change, support the client's expectations and increase of financial performance. When employees become capable and committed their intellectual capital is reflected in financial results of company.

Main activities of employee contribution management include: hearing, answering and finding ways for supporting the changing demands of employees. Upon the increase of employee's demand the professional and line directors as the champions must find innovative tools for hearing the employee's ideas and creating a sense of ownership in them regarding their work. These champions help the psychological agreement between the employee and company, also, they provide new tools to support their demands.

\section{Management of Transformation and change}

The fourth role of professional is management of transformation and change. Transformation means the fundamental change in company's culture. As culture guards and change factors, the professionals manage the organizational transformation. It also points to the ability of organization in improving the plans and making innovations and decreasing the time cycle of organization's activities.

The professionals help the identification and executions of change process. The result is capacity for change. When the companies (firms) undergo changes, the human resource directors as the strategic partner help the employee to leave the old culture and accept the new one. As factors of change, these directors help the organizations to face the conflicts within every organizational change. Often, change must happen with a look into the past. The professional must respect the past while playing their futuristic role. This means respect for business history and traditions. Clearly, becoming a change factor is a part of value - adding role of the professional as the business partners. Their duties include: identify and defining the problems, creating trust - based relationships, solving the problems, designing and executing the promotion plans.

Ulrich (1997) in research about the capabilities of human resource professionals found that the capability of change management is the most significant factor for success of a professional in human resource. These professional help the creation of change, understand the key change process and create commitments to them. Also, they have certain that the changes happen as expected (Ghelich, 2007).

\section{Human resources management in this study}

A human resource manager stated in the present study refers to the emerging human resource. Such a novel community is comprised of HR professionals, executive and headquarters managers, consultants and other vendors as well as service providers. Human resource role assessment in the present study is a kind of selfassessment introduced by David Ulrich. There are four new general roles for human resource management based on the model used in this study (Ulrich model) as 
Table 2. Percents of demographic aspects.

\begin{tabular}{ccccccccccc}
\hline \multicolumn{3}{c}{ Management level (\%) } & \multicolumn{3}{c}{ Education level } & \multicolumn{2}{c}{ Marriage } & \multicolumn{2}{c}{ Gender } & Demographic \\
Operation & Junior & Senior & $\begin{array}{c}\text { Masters } \\
\text { and higher } \\
\text { degrees }\end{array}$ & Bachelors & diploma & Single & Married & Female & Male & \begin{tabular}{c} 
aspects \\
\hline 44.5
\end{tabular} \\
\hline & 45.3 & 10.25 & 16.4 & 77.3 & 6.2 & 15 & 85 & 68 & 32 & $\begin{array}{c}\text { percent } \\
\text { total }\end{array}$ \\
\hline
\end{tabular}

follow:

(1) Strategic human resource management: this role focuses on organizational strategies and human resource practices along with business strategy (or organization). The metaphor of this role is known as "strategic partner" (HRAs a strategic partner).

(2) Management of the firm Infrastructure: creation of the organizational infrastructure is the traditional role of human resources. This role requires appropriate design and effective implementation of recruiting processes, training, evaluation, compensation, and promotion as well as employees job rotation management throughout the organization. The metaphor used as the company's infrastructure role is known as "Administrative Expert".

(3) Management of employee contribution: such role of human resource professionals includes their involvement in current issues, concerns and staff requirements. The metaphor used in this role is known as "Employee Champion".

(4) Management of transformation and change: transformation refers to the basic change of the culture. Professionals of human resource fields as protectors and modifiers of culture carry out the organizational change management. The metaphor used in this part is known as "Change Agent" (Ghelich, 2007).

\section{METHODS}

The present study is an analytical-descriptive research carried out among 167 human resource managers (22 senior managers, 88 junior managers and 57 operation managers) in all specialized and sub specialized hospitals operating under the supervision of Tehran University Medical Science (located in Tehran) during first 6-month period of the year 2011. Sample statistics used in the study include senior managers (executive and Matrons), junior managers (supervisors, finance managers and administrators) and operation managers (foremen and head of bedridden unit) in the investigated hospitals which the foremen and head of bedridden unit under the supervision of the supervisors and the supervisors under the supervision of the Matrons, in addition the finance managers and administrators under the supervision of the executive. They are all included in the present research due to limited number of senior and junior managers and head of various administrations.

The data gathering tool used in the present study was a two-step questionnaire. The questionnaire was comprised of demographic aspects and roles of human resource management in which evaluation of human resource service quality and the quality perception are discussed in the latter one. Human resource questionnaire is standard and confidential which could be used easily (Ulrich, 1997). Besides, the questionnaire has undergone some minor changes by the author to fit the personnel conditions working in hospitals such as modification of some words that had no significance in the questionnaire concept and the employee's viewpoint.

The questionnaire included 40 queries ( $4^{*} 10$ queries) in a 5-ponit Likert scale (lowest score equals to 1 and highest one equals to 5). General score of quadruple roles (ranging from 50 to 200) illustrates the quality of human resource services. Scores beyond 160 indicate the high quality services of human resource while scores below 90 demonstrate the low quality. Each role mentioned in the foregoing is assigned a score in the range of 10 to 50 (Ghelich, 2007).

Researcher administered questionnaire in person. Sample statistics are all human resource managers in hospitals in the study included in the present research due to limited number of senior and junior managers and head of various administrations. There were 128 total questionnaires gathered from 11 hospitals in the study in which 39 questionnaires $(30.5 \%)$ were eliminated from the study due to lack of information (some of them did not return and some did not complete and some return with no response).

Findings collected from questionnaire data illustrated as statistical tables, graphs and numerical indicators. Statistical analysis was accomplished though k-square test, t-test and analysis of variance (ANOVA) using SPSS software as the platform. $\mathrm{P} \leq 0.05$ considered statistically significant.

\section{RESULTS}

First demographic aspects were determined (Table 2) and most of the people in the present study have been 35 to 45 years old and most of responders had 15 to 25 years background experience. The roles mentioned previously could be ranked as strategic partner, administrative personnel, change agent and employee champion with the average score of $33.42,32.86,29.41$ and 27.43 , respectively revealed to be the most important ones. Hospitals of the universities investigated in the study got the average score of 122.7 which indicates the average level of human resource services in those hospitals (Table 3 ).

Based on the results of the study, maximum score among 4 roles of human resource management in male group revealed to be the "Strategic partner" with an average score of 33.8 while this criterion in female group was the "Administrative expert" with an average score of 33.5. Minimum score in both male and female groups was assigned to "Employee champion" (male group: 27.6 and female group: 27.3). Average quality level of human 
Table 3. Rating profile of human resource management roles.

\begin{tabular}{clcc}
\hline Row & Dimensions & Mean & Standard deviation \\
\hline 1 & Strategic partner & 33.4 & 9.2 \\
2 & Administrative expert & 32.9 & 8.5 \\
3 & Employee champion & 27.4 & 9.9 \\
4 & Change agent & 29.4 & 9.2 \\
5 & Total & 122.7 & 32.5 \\
\hline
\end{tabular}

Table 4. Rating profile of human resource management roles Gender base.

\begin{tabular}{clccc}
\hline \multirow{2}{*}{ Row } & \multirow{2}{*}{ Dimensions } & Female & Male & \multirow{2}{*}{ P-value } \\
\cline { 2 - 3 } & & Mean \pm SD & Mean \pm SD & \\
\hline 1 & Strategic partner & $33.2 \pm 9.2$ & $33.8 \pm 9.3$ & NS \\
2 & Administrative expert & $33.5 \pm 8.9$ & $31.6 \pm 7.4$ & NS \\
3 & Employee champion & $27.3 \pm 10.4$ & $27.6 \pm 9.0$ & NS \\
4 & Change agent & $29.5 \pm 9.5$ & $29.2 \pm 8.7$ & NS \\
5 & Total & $122.9 \pm 35.0$ & $122.3 \pm 30.5$ & NS \\
\hline
\end{tabular}

Table 5. Rating profile of human resource management roles marriage base.

\begin{tabular}{clccc}
\hline \multirow{2}{*}{ Row } & \multirow{2}{*}{ Dimensions } & Married & Single & \multirow{2}{*}{-value } \\
\cline { 3 - 4 } & & Mean \pm SD & Mean \pm SD & \\
\hline 1 & Strategic partner & $33.7 \pm 8.9$ & $33.2 \pm 9.7$ & NS \\
2 & Administrative expert & $33.3 \pm 8.0$ & $31.7 \pm 9.8$ & NS \\
3 & Employee champion & $27.8 \pm 9.5$ & $26.3 \pm 11.7$ & NS \\
4 & Change agent & $29.8 \pm 8.8$ & $28.3 \pm 10.6$ & NS \\
5 & Total & $124.0 \pm 32.2$ & $119.5 \pm 37.1$ & NS \\
\hline
\end{tabular}

resource services have been 122.3 (male) and 122.9 (female), however statistical tests didn't show significant differences between the roles and the quality of human resource services in both male and female group (Table 4).

Maximum score in married and single groups revealed to be 33.7 and 33.2 , respectively that assigned to "Strategic partner" while the minimum score in both groups was allocated to "Employee champion" with the 27.8 and 26.3 score levels respectively. Average quality level of human resource services in married and single groups were also indicated as 124.0 and 119.5, respectively in which it hadn't shown any significant differences between average roles and the quality level of human resource services in both sections (Table 5).

Maximum score in all educational levels assigned to the "Strategic partner" and the minimum one had been "Employee champion". Average quality level of human resource services have been 123.8, 122.8 and 131.8 in diploma, bachelor and master groups, respectively. Besides, the statistical test did not show significant differences among average levels of the fore roles (strategic partner: $\mathrm{P}=0.02$, Administrative expert:
$\mathrm{P}=0.008$, employee champion: $\mathrm{p}=0.05$, change agent: $p=0.02$, quality of human resource services: $p=0.01$ ) (Table 6).

Senior, junior and operation managements with the $38.0,32.8$ and 32.9 scores, respectively assigned the maximum and minimum scores to the "Strategic partner" and "Employee champion", respectively (senior management: 31.2 , junior management: 27.4 and operation management: 26.6). Average quality of human resource services revealed to be 140.0, 121.2 and 129.0 in senior, junior and operation managements respectively. Besides, there have been no significant differences between "change agents" of various management levels $(P=0.05)$ (Table 7).

Having analyzed the quality levels of human resource services, one may conclude that maximum percentage of responders $(75.2 \%)$ was assigned to average equality (Figure 2). Maximum percentage level among management groups has been assigned to the average quality (senior management: $69.2 \%$, junior management: $80.4 \%$, operation management: $71.4 \%$ ).

There has been no low quality level reported by senior management $(0 \%)$ while the maximum quality level 
Table 6. Rating profile of human resource management roles based on education level.

\begin{tabular}{clccccc}
\hline \multirow{2}{*}{ Row } & \multirow{2}{*}{ Dimensions } & Diploma & skilled & Bs & Ms and Ph.D & \multirow{2}{*}{ P-value } \\
\cline { 3 - 6 } & & Mean \pm SD & Mean \pm SD & Mean \pm SD & Mean \pm SD & \\
\hline 1 & Strategic partner & $20.8 \pm 9.0$ & $37.5 \pm 6.2$ & $33.5 \pm 9.0$ & $34.9 \pm 9.1$ & $\mathrm{P}=.02$ \\
2 & Administrative expert & $19.3 \pm 7.8$ & $30.0 \pm 4.4$ & $33.2 \pm 8.4$ & $34.4 \pm 7.6$ & $\mathrm{P}=.008$ \\
3 & Employee champion & $15.3 \pm 2.2$ & $28.0 \pm 2.9$ & $27.3 \pm 10.3$ & $30.2 \pm 8.0$ & $\mathrm{P}=.05$ \\
4 & Change agent & $17.3 \pm 6.3$ & $28.3 \pm 6.8$ & $29.4 \pm 9.1$ & $32.3 \pm 8.8$ & $\mathrm{P}=.02$ \\
5 & Total & $72.5 \pm 23.0$ & $123.8 \pm 16.1$ & $122.8 \pm 33.6$ & $131.8 \pm 30.0$ & $\mathrm{P}=.01$ \\
\hline
\end{tabular}

Table 7. Rating profile of human resource management roles based on management level.

\begin{tabular}{clcccc}
\hline \multirow{2}{*}{ Row } & \multirow{2}{*}{ Dimensions } & Senior & Junior & Operation & \multirow{2}{*}{ P-value } \\
\cline { 3 - 5 } & & Mean \pm SD & Mean \pm SD & Mean \pm SD & \\
\hline 1 & Strategic partner & $38.0 \pm 7.6$ & $32.8 \pm 9.1$ & $32.9 \pm 9.5$ & NS \\
2 & Administrative expert & $36.4 \pm 6.8$ & $32.0 \pm 7.6$ & $32.9 \pm 9.6$ & NS \\
3 & Employee champion & $31.2 \pm 8.5$ & $27.4 \pm 9.5$ & $26.6 \pm 10.6$ & NS \\
4 & Change agent & $34.5 \pm 7.3$ & $29.0 \pm 8.8$ & $28.6 \pm 9.8$ & $\mathrm{P}=0.05$ \\
5 & Total & $140.0 \pm 27.7$ & $121.2 \pm 30.7$ & $129.0 \pm 36.7$ & NS \\
\hline
\end{tabular}

\section{Human resources services quality}

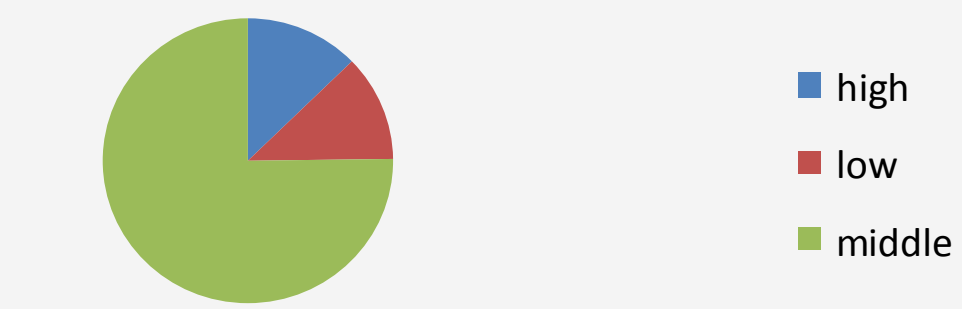

Figure 2. Rating profile of Human resources services quality levels.

$(30.8 \%)$ revealed to be in this group (Figure 3).

\section{Conclusion}

The most important organizational resource is known as its human resources which move toward the organization objectives through proper conduct and leadership. One of the main issues of the society is stated as inefficiency and lack of effectiveness in the organizational management such as universities (Asefzadeh et al., 2005).

In today's' world organizations can rely on their own strengths to progress and obviate their week points; they can utilize growth opportunities using such viewpoint. It is obvious that such issue in the management practice is regarded as the most valuable organizational resources (human resources) specifically by hospitals as a health service providing institute because they deal with vital issues, that is, the human life. The present study has aimed at strength and average points of the human resource management in hospitals based on their roles. Results are validated through researches carried out before (Eghbal et al., 2007; Maleki and Izadi, 2008).

Eghbal et al. (2007) concluded the strong point of the organization as their strategy and guideline while their average points related to the personnel. In addition, he concluded that personnel had assigned $39 \%$ of scores to themselves which indicate the importance of the human resource field and role of management style (Maleki and Izadi, 2008).

Maximum score estimated in the present study is assigned to the "strategic partner" that could be assumed as the strong point of the human resource management in hospitals located in the University of Tehran realm, while the minimum score is allocated to the employee champion which requires improvement in the human resource management of the university. Regarding the 


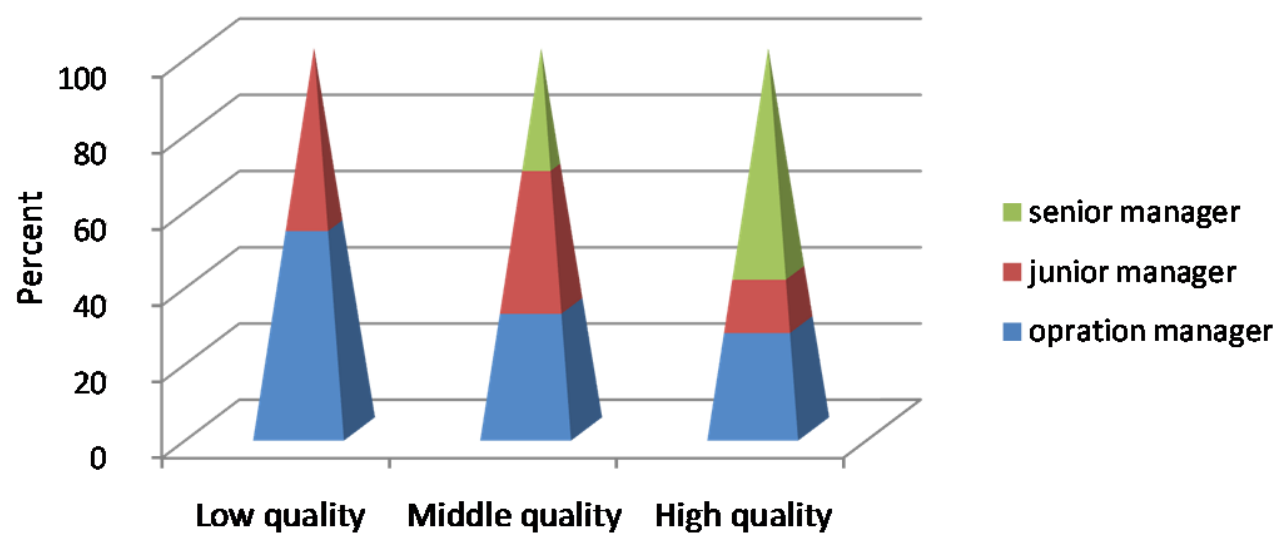

Figure 3. Human resource management quality level based on management levels.

relationship among the four roles of the human resource management, it could be concluded that the findings of the present study are in accordance with research carried out by Hamidi et al. (2009). Based on their research, human resource role influence the organizational agility and requires a combination of 7 activities of human resource management as; job design, employment, education, training and development, performance management, personnel relations, business communication. On the other hand findings of human resource activities indicate that its components are related to each other which should be revised along with organizational restructuring (Hamidi et al., 2009). The 7 activities of human resource management are correlated with its 4 management roles (as there are relationships among the 7 component of the human resource management). In the same way the present study concluded that there are positive significant correlation among the four roles of strategic partner, change agent, administrative expert and employee champion so the research findings are validated.

Based on a research study conducted by Azar et al. (2009), all the components of human resource management model are fairly divided and duties of the human resource organization are cauterized into various classifications based on the mutual relationships between personnel as the first issue and then training together with education including: performance analysis training. Service compensations seemed to be ranked as high; however it is categorized as sixth one. Such ranking indicates the effective planning in personnel relationships, that is, valorizing the personnel and their education as well as training are the most influential factors in personnel perception respect to implementation of costly plans for service compensation that require a comprehensive development of human resource management systems and enhancing the personnel capabilities and supporting them (Azar et al., 2009).

Results of the aforesaid research indicated the average quality level of all human resource services in hospitals located in the study universities which emphasizes on the existing gap between the current level and optimum one. Such result is in accordance with findings of a research study conducted by Mirfakhraldini et al. (2009) they stated that the cultural dimension of organization in healthcare centers based on the EFQM model 2009 are not in an appropriate state. Two finding of the aforesaid study could be suggested: Fist, medical and healthcare centers are dealing with difficulties regarding organizational culture which is related to the human resource management viewpoint and its role in the organization, so illustrate the necessity of paying attention to such field in the medical and healthcare centers as well as roles and responsibilities assigned for HR managers.

Second, as the findings of the present study indicate, there are some weak points in the "employee champion" role that requires periodical revisions in the studied hospital. In addition the study showed that human resource in the hospitals on the country is potentially capable of presenting better performance level. Such potential would be realized through changes of attitude toward their capabilities and attempts to make their improvements.

Improvement to human resource management is required to enhance the capability of hospitals in order to provide people with qualified healthcare services and safety. This issue necessitates competent board of directors take charge of all responsibilities to continuously improve the personnel conditions in the organization. Focus on human resource challenges and its effective strategies should be regarded as senior management preferences (El-Jardali et al., 2009). Therefore HR managers require a potential position in the organization so they can contribute in the strategic planning and methods of effective organizational approaches in accordance with the organizations' objectives. It could be inferred from the findings of the study that HR managers are not directly involved with the stake-holders' issues 
and the organization profitability; however they should be underestimated, because the desirable consequences of the organization and its stakeholders is placed in the organization support unit (Friedman, 2009).

Other research carried out in Afghanistan, South Africa and South Sudan indicated that leaders of healthcare unit have been successful in different units; multi-dimensional approach, comprehensive planning, human resource development plan guideline, expert human resource management, extensive recruiting system, training, testing, heal certificate, periodical apprentice assessment before recruiting and a unique HR database throughout the country.

This study states that leaders of HR could adopt a comprehensive viewpoint and work on stakeholders to improve planning, management \& training of healthy employees to contribute positively on the performance of the health sector (Schiffbauer, 2008).

The importance of the HRM in success or failure of the healthcare system in New Zealand made the government to enact a law for clients and employers to be a "good client"; based on the law, a good client is the one which is involved with the best performance of HRM (Edgar et al., 2007). The author believes that performance analysis alone cannot be responsible for increasing performance demand of $\mathrm{HR}$ in existing organizations so that it contributes in their excellence. It should evaluate the existing viewpoints and ideas as well as the HR manager role in charge, so to identify strength and weakness points and present a new definition for the role of HRM in the organization.

Rules and regulations for the healthcare policymaking and management are regarded as the central part of any potential solutions for the health system performance (Buchan, 2004). The most important rule and policies are related to HR field that could be accomplished through cooperation of policymakers and, decision makers in this field to achieve an acceptable level.

Since findings of the present study reveals the priority of the HRM position in the hospitals ( $1^{\text {st. }}$ : strategic partner, $2^{\text {nd: }}$ administrative expert, $3^{\text {rd: }}$ change agent and $4^{\text {th }}$ : employee champion). Regarding the positive correlation among four HRM roles and respect to quality services as well as average quality level of HR services in the hospitals, it could be concluded that planning and utilization of HRM strong points (that is the same high ranked roles: strategic partner and: administrative expert) together with improvement of HR potential average points (that is the low ranked roles: change agent and employee champion), enhancement of HR services could be accomplished in healthcare centers.

As improving the planning scheme, management style and training the employees would result in positive impact on the performance level of healthcare unit, planning for improvement of the HR managers' capabilities may contribute in enhancement of their service quality presented to the organizations and finally provide the end-user society with the improved healthcare services.

\section{ACKNOWLEDGMENTS}

This article is extracted from thesis that was supported financially by School of Health, Qazvin University of Medical Sciences. At the end the researcher sincerely appreciates all the efforts of people that have helped us in this study research in various ways.

\section{REFERENCES}

Asefzadeh S, Mohebbifar R, Shirali H(2005). Leadership Styles and the performance of the managers at Qazvin University of Medical Sciences. J. Qazvin Univ. Med. Sci. 34:56-62. [In Persian].

Azar A, Safari S (2004). Making organizational excellence model with an data covering analyses approach. Tehran university electronic publication cite. http://journals.ut.ac.ir. 4(13):65-95. [In Persian]

Azar A, Khaefollahy A, Danayeefard H, Alipourdarvishi Z (2009). Desining equitably human resource management model(definitive phasic approach). J. Hu. Res. manage.1(2): 1-28. [In Persian].

Schultz BE (1997). Modeling HRM in Context: Examining the Role of Human Resource Manager Discretion. UMI. Dissertation submitted to the graduate faculty of the Louisiana state university and Agricultural and Mecanical College.

Buchan J (2004). What difference does ("good") HRM make?. Inter J. for Hu. Res. for Health, cited in: http://www.csb.gov.hk/english, date of access: 24 October 2010.

Edgar F, Geare A (2007). Legislating for Best Practice HRM: The New Zealand Approach. ProQuest Psychol J. Public Personnel Management. Fall 2007; 36(3):183.

Eghbal F, Yarmohamadian M, Siadat S (2007). Assessment of human resourse management performance in the Sfahan university of medical science based on EFQM with both approach questionnaire \& profroma; Cited in Scientific information database in http://www.sid.ir. J. Health. Manage. 11(34): 49-58. [In Persian]

El-Jardali F, Tchaghchagian V, Jamal D (2009). "Assessment of human resources management practices in Lebanese hospitals". Health Management and Policy Department, Faculty of Health Sciences, American University of Beirut, Beirut, Lebanon. Hum Resour Health. Cited in PubMed in http://www.ncbi.nlm.nih.gov. Date of access: 24 October 2010.

Friedman B (2009). Human Resource Management Role Implications for Corporate Reputation. Cited in http://www.palgrave-journals.com Date of access: 24 October 2010.

Ghelich li B (2007). HR excellence; Assessment, Planning and Improvement. Saramad publication. [In Persian]

Hamidi N, Hasanpour A, Kiyayee M, Mosavi Seyed H (2009). Human resourse management role in organizational agility. Cited in Scientific information database in http://www.sid.ir. J. Industrial .manage: 4(8). 111-127. [In Persian]

Mahdavi M (2006). Comparetion Study of Orgarizational Commitment status \& abandonment inclination of General hospitals personnel in Tehran. Health care management Thesis. Faculty of hygiene. Tehran university of medical science. [In Persian]

Maleki M, Izadi A (2008). Comparison results in tow Tehran Tamine Ejtemayee hospitals on the basis of Organizational Excellence Model. J. Qazvin Univ. of Med. Sci. 47:63. [In Persian] Mirfakhraldini Seyed H, Farid D, Sayadi Touranlou H (2009). Using EFQM model in analyses organizational culture dimensions of remedy service centers (case study: Yazd hospitals). J. Yazd Shahid Sadoughee Univ. of Med. Sci. 17(2): 30-42.[In Persian]

Mirsepasi N (2005). Human resources strategic management \& labour relation with a glance at globalization trend. Mir publishing institute; Tehran. [In Persian].

Mostafayee D (2004). Estimate needed human resources of Tehran 
university of medical sience hospitals according to the ministry of health's personally rules \& standards. Health care management Thesis. Faculty of hygiene. Tehran university of medical science. [In Persian].

Saadat E (2007). Human resource management. study \& collection of human sience books of universities organization(SAMT); Tehran. [In Persian]

Schiffbauer J, Barrett O'Brien J, K Timmons B, N Kiarie W (2008). The role of leadership in $\mathrm{HRH}$ development in challenging public health settings. licensee BioMed Central Ltd. Management Sciences for Health, Cambridge, MA, USA. Crystal Hill Consulting, Nairobi, Kenya. Cited in http://ukpmc.ac.uk. Date of access: 24 October 2010.
Torabipour A (2004). Studying relationsheep leader's styles \& contrast management strategies omong bosses, management \& responsible in the Lorestan medical university's hospitals. Health care management Thesis. Faculty of hygiene. Tehran university of medical science. [In Persian]

Ulrich D (1998). Delivering results a new mandate for human resources Professional. Harvard Business Review.

Ulrich D(1997). Human resource champions. The Next Agenda for Adding Value and Delivering Results. Harvard Business School Press: Boston. Massachusetts. 